\title{
Open speeds on Northern Territory roads: not so fast
}

\section{Road safety should remain a public health priority, not a political issue}

A

nnual road deaths in Australia have decreased from 7.9 to 5.2 per 100000 population in the period from 2004 to 2013 (Box). ${ }^{1}$ In contrast to the national figures, the Northern Territory has recorded a mean of 21.8 deaths per 100000 over the same period.

There are many possible factors contributing to this large discrepancy. Among NT road users, alcohol usage is high and seatbelt usage is low. ${ }^{2}$ Additionally, NT roads are almost invariably single lane and unseparated, many are unsealed, they are subject to the extremes of weather and are also exposed to wandering livestock and wildlife. Consequently, NT roads have attracted the lowest of Australian Road Assessment Program safety ratings, with over half having one and two stars out of five. ${ }^{3}$ The NT is unique in many ways and these differences threaten the survival of road accident victims. Road traffic is light and, as a consequence of this, victims may not be found for many hours after an accident. Hospitals and retrieval assets are sparse, resulting in prehospital times of many hours. The "golden hour" of trauma that window immediately after injury when medical intervention can be life-saving - seldom exists for Territorians in remote areas.

\section{"What seems to be lacking in this debate is a dispassionate examination of the available evidence"}

Indigenous Australians comprise nearly $30 \%$ of the NT population, and most of these people live in remote areas. The risk of road trauma is magnified in these remote communities, as cultural and linguistic differences are a barrier for driver licensing and training and there is a paucity of public transport, and yet there are frequent cultural demands for shortnotice mass transport. ${ }^{4}$

\section{Changing policy with changing governments}

Before 2007, there was no speed limit on most NT highways, and drivers were free to travel at whatever speed they felt comfortable with. In 2007, in response to the high road toll, the NT Government introduced speed limits of $130 \mathrm{~km} / \mathrm{h}$ on the four main highways and $110 \mathrm{~km} / \mathrm{h}$ on other rural roads. ${ }^{5}$ Since then, differing political, professional and public opinions have been discussed frequently in the NT media. These speed limits were reconsidered in 2012, and
David J Read MBBS, FRACS

National Critical Care and Trauma Response Centre, Darwin, NT.

DavidJ.Read@nt.gov.au doi: 10.5694/mja15.00239

Online first 22/06/15

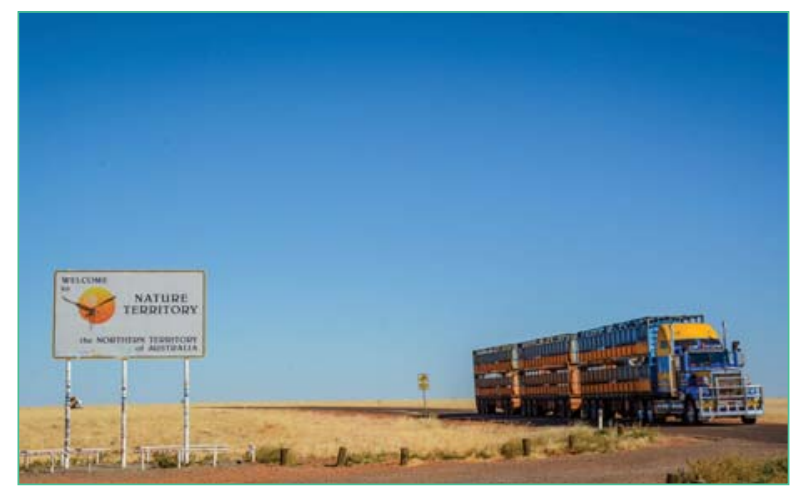

the NT government made an election promise to conduct a review on the feasibility of reintroducing open speeds. ${ }^{6}$ The government commissioned reports from road safety experts, but this information remains cabinet-in-confidence. In February 2014, the NT Government reintroduced open speeds for a $200 \mathrm{~km}$ section of the Stuart Highway on a trial basis, ${ }^{7}$ despite voiced concerns from medical, policing and road safety groups. The response from the current NT Government to these concerns is to cite the role of fatigue, to emphasise the roles of alcohol and seatbelts, to deny that speed is a major factor in many crashes and to promote individual driver responsibility. ${ }^{7}$

\section{Vehicular speed and crash risk}

The relationship between speed and a motor vehicle collision goes beyond the kinetic energy released

Comparison of annual road deaths per 100000 population in the Northern Territory with the national total, 2004-2013*

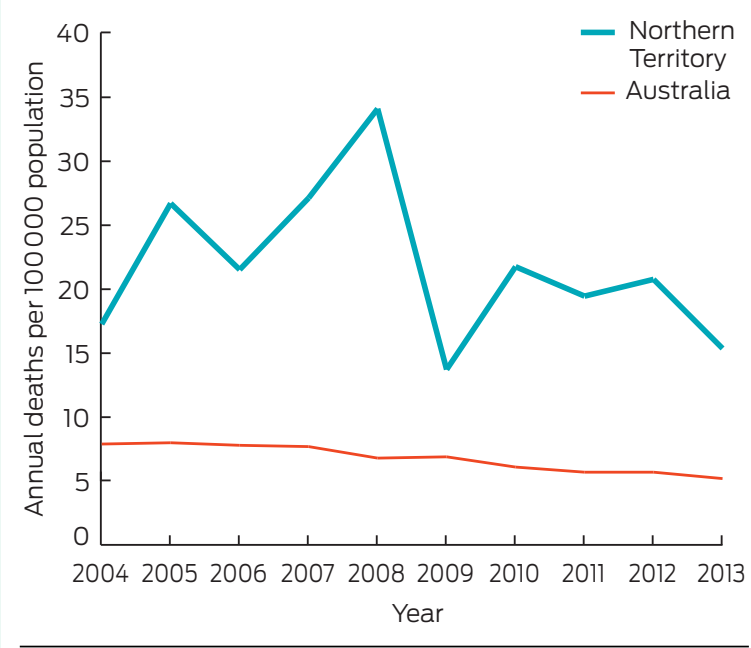

* Data from: Bureau of Infrastructure, Transport and Regional Economics. Road deaths Australia: 2013 statistical summary.' 
being proportional to the product of mass and velocity squared. Researchers have developed several formulas to describe the multifactorial nature of road accidents, involving multiple variables; however, in each of these models, speed remains a decisive factor. An increase in vehicular speed increases crash risk either exponentially or to a power ratio. ${ }^{8}$ Modelling has suggested that the greater the difference in speed between two vehicles, the greater the crash risk for both the slower and the faster vehicle. ${ }^{8}$ The implications of a mix of open speed and speedrestricted vehicles, such as towing vehicles, heavy vehicles and probationary drivers, are obvious. Further, Australian and international case-control studies have shown that reducing posted speed limits by $10 \mathrm{~km} / \mathrm{h}$ on rural roads decreases crash risk by $20 \%-25 \%$. Multiple examples of this are included in the National Road Safety Strategy 2011-2020. ${ }^{9}$

What seems to be lacking in this debate is a dispassionate examination of the available evidence. Allowing individual motorists to drive to conditions seems optimistic and discounts that there will always be a cohort of inexperienced drivers. This policy seems to place blame on individual motorists, overlooking the conditions that increase the risks of fatal crashes. Higher vehicle speeds are promoted by lobby groups as a solution to reducing fatigue. While combating fatigue is important in improving road safety, swapping one risk factor for another is not the solution. Campaigns to combat drink driving and poor rates of seatbelt use are appropriate, but road safety is a package, and a vital element of the package is missing.

The small numbers involved make statistical interpretation difficult. The Australian road deaths database shows a decrease in fatalities of 3.4 per year on those NT roads with speed limits of $110 \mathrm{~km} / \mathrm{h}$ and above after the abolition of open speeds (mean deaths: 2000-2006, 31.1 per year; 2007-2014, 27.7 per year). ${ }^{10}$ For every road death in Australia, 23 other people are hospitalised as a result of a road crash, ${ }^{9}$ which amplifies the potential societal benefit of any reduction in speed limit. Other legislative measures, infrastructure and trauma system improvements are likely to have contributed to this reduction, but attempting to minimise the role of speed in crash risk would seem unwise.

\section{The Northern Territory needs a stronger road} safety package

Trauma is too often considered an accident when it should be considered a preventable disease. We understand the causes and effects and we know, to an extent, how to prevent this trauma from occurring. Every crash is multifactorial, and alcohol and seatbelt use should remain a focus of a strong road safety package. However, allowing unlimited speed on major highways sends the wrong message to the NT population, especially when they are already three times more likely to die on the roads than people living in other parts of Australia, and at a rate that is equivalent to that in many low- and middle-income countries. ${ }^{11}$ The available evidence in the literature suggests that the piecemeal reintroduction of open speeds on the highways of the NT will eventually result in an increased number of fatalities and serious injuries. The NT Government should strengthen its road safety package and tailor it to the unique needs of its population, not abandon components due to popular demand. A comment from scientist Richard Feynman on the interplay between science and politics resonates here:

For a successful technology, reality must take precedence over public relations, for Nature cannot be fooled.

Acknowledgements: I acknowledge Christopher Gowing for his assistance in preparing this manuscript.

Competing interests: No relevant disclosures.

Provenance: Not commissioned; externally peer reviewed.

References are available online at www.mja.com.au. 
1 Australian Government, Bureau of Infrastructure, Transport and Regional Economics. Road deaths Australia: 2013 statistical summary. Canberra: Department of Infrastructure and Regional Development, 2013. https://www.bitre.gov. au/publications/ongoing/files/RDA_Summary_2013.pdf (accessed Feb 2015).

2 Northern Territory Government Department of Transport. Northern Territory 2014 Road Injury Statistical Summary. Darwin: Department of Transport, 2014. http://www. transport.nt.gov.au/_data/assets/pdf_file/0004/45769/ NT-Road-Crash-Statistical-Summary-2014-2005-14trends-8-1-15.pdf (accessed Mar 2015).

3 Australian Automobile Association. Star rating: Australia's national network of highways. Australian Road Assessment Program Star Ratings Report. Canberra: AAA, 2013. http:// www.raa.com.au/documents/2013-ausrap-report (accessed Mar 2015).

4 Helps Y, Moller J, Kowanko I, et al. Aboriginal people travelling well: issues of safety, transport and health. Adelaide: Department of Infrastructure, Transport, Regional Development and Local Government, 2008. (Road Safety Grant Report 2008-01). https://www.infrastructure.gov.au/ roads/safety/publications/2008/pdf/RS

5 Martin C, Northern Territory Government Chief Minister. Road changes to save lives [media release]. 2 Nov 2006.
https://www.walk.com.au/pedestriancouncil/Page. asp?PagelD=1908 (accessed Mar 2015).

6 Mills T. Summary snapshot: road safety. Deadly serious reducing risks on our roads. Darwin: Country Liberals, 2012. http://www.countryliberals.org.au/uploads/Road\%20 Safety\%20Policy.pdf (accessed Feb 2015).

7 Northern Territory Government Department of Transport. Government speed limit trial announced. Darwin: DoT, 2013. http://www.transport.nt.gov.au/publications/ newsroom/2013/government-speed-limit-trial-announced (accessed Feb 2015).

8 Aarts L, van Schagen I. Driving speed and the risk of road crashes: a review. Accid Anal Prev 2006; 38: 215-224.

9 Australian Transport Council. National Road Safety Strategy 2011-2020. http://www.infrastructure.gov.au/roads/safety/ national_road_safety_strategy/files/NRSS_2011_2020.pdf (accessed Feb 2015).

10 Australian Government Department of Infrastructure and Regional Development. Australian road deaths database. Canberra: DIRD, 2015. http://www.bitre.gov.au/statistics/ safety/fatal_road_crash_database.aspx (accessed Feb 2015).

1 World Health Organization. Global Health Observatory (GHO) data. Number of road traffic deaths. Geneva: WHO, 2010. http://www.who.int/gho/road_safety/mortality/traffic_ deaths_number/en (accessed Mar 2015). 